\title{
Serotonin transporter knockout rats show improved strategy set-shifting and reduced latent inhibition
}

\author{
Lourens J.P. Nonkes, ${ }^{1}$ Ilse I.G.M. van de Vondervoort, ${ }^{1}$ Mark J.C. de Leeuw, ${ }^{1}$ \\ Linda P. Wijlaars, ${ }^{1}$ Joseph H.R. Maes, ${ }^{2}$ and Judith R. Homberg ${ }^{1,3}$ \\ ${ }^{1}$ Donders Institute for Brain, Cognition, and Behaviour, Centre for Neuroscience, Department of Cognitive Neuroscience, Radboud \\ University Nijmegen Medical Centre, 6525 EZ, The Netherlands; ${ }^{2}$ Donders Institute for Brain, Cognition, and Behaviour, \\ Centre for Cognition, Department of Biological Psychology, Radboud University Nijmegen, 6525 HR Nijmegen, The Netherlands
}

\begin{abstract}
Behavioral flexibility is a cognitive process depending on prefrontal areas allowing adaptive responses to environmental changes. Serotonin transporter knockout $\left(5-\mathrm{HTT}^{-/-}\right)$rodents show improved reversal learning in addition to orbitofrontal cortex changes. Another form of behavioral flexibility, extradimensional strategy set-shifting (EDSS), heavily depends on the medial prefrontal cortex. This region shows functional changes in 5-HTT ${ }^{-1}$ rodents as well. Here we subjected $5-\mathrm{HTT}^{-/-}$rats and their wild-type counterparts to an EDSS paradigm and a supplementary latent inhibition task. Results indicate that 5 - $\mathrm{HTT}^{-/-}$rats also show improved EDSS, and indicate that reduced latent inhibition may contribute as an underlying mechanism.
\end{abstract}

[Supplemental material is available for this article.]

Serotonin (5-HT) is an ancient molecule that subserves a link between the organism and the environment, and thereby mediates adaptive responses to environmental changes. This is not only reflected by its role in emotional processing (Hariri and Holmes 2006; Merens et al. 2007; Lowry et al. 2008), but also cognitive functions (Cools et al. 2008; Homberg and Lesch 2011). The serotonin transporter (5-HTT) tightly controls 5-HT levels via its reuptake from the synaptic cleft, making it an important modulator of 5-HT's actions. Hence, factors that affect 5-HTT availability are likely to affect cognitive processing. One well-studied factor in the human and nonhuman primate population is the 5-HTT-linked polymorphic region (5-HTTLPR). It encompasses two genetic variations in the promoter of the 5-HTT (SLC6A4) gene, of which the short (s) allelic variant is associated with reduced transcription of the 5-HTT gene compared with the long (1) allelic variant (Lesch et al. 1996). Early studies showed that s-allele carriers exhibit anxiety-related traits (Lesch et al. 1996) and are at a greater risk for developing depressive symptoms in interaction with early life stress (Caspi et al. 2003). Furthermore, they show functional and anatomical alterations in prefrontal cortical areas (Hariri et al. 2002; Pezawas et al. 2005; Pacheco et al. 2009) important for behavioral flexibility (Dolan 2007; Ragozzino 2007; Keeler and Robbins 2011), which may contribute to improved reversal learning and Wisconsin Card Sorting Test performance (containing extradimensional set-shifting elements) (Borg et al. 2009; Jedema et al. 2010; Homberg and Lesch 2011).

In analogy with the 5-HTTLPR findings, 5-HTT knockout $\left(5-\mathrm{HTT}^{-/-}\right)$rats and mice show-next to increased anxiety- and depression-like behaviors (Kalueff et al. 2010)—improved performance in a reversal learning task (Brigman et al. 2010; Nonkes et al. 2011) and functional changes in prefrontal areas subserving reversal learning (orbitofrontal cortex; OFC) and extradimensional set-shifting (medial prefrontal cortex; mPFC) (Ragozzino 2007; Wellman et al. 2007; Nonkes et al. 2010; Keeler and

\footnotetext{
${ }^{3}$ Corresponding author.
}

E-mail j.homberg@cns.umcn.nl.

Article is online at http://www.learnmem.org/cgi/doi/10.1101//m.025908.112.
Robbins 2011; Pang et al. 2011). Therefore we hypothesized that 5 -HTT ${ }^{-/-}$rats also show improved extradimensional set-shifting. To this end, we tested the animals in an extradimensional strategy set-shifting (EDSS) task, in which they had to shift from the use of an egocentric discrimination strategy to a visual stimulus-based variant in order to obtain food reward. We also tested a separate group of animals in the latent inhibition test to investigate whether differences in strategy set-shifting may be due to enhanced associative stimulus-reward learning.

All experiments were approved by the Committee for Animal Experiments of the Radboud University Nijmegen Medical Centre, Nijmegen, The Netherlands. Experimental animals (Slc6a41Hubr) (Homberg et al. 2007) were derived from crossing heterozygous 5-HTT knockout $\left(5-\mathrm{HTT}^{+/-}\right)$rats that were outcrossed for at least 10 generations with wild-type Wistar rats (Harlan Laboratories, The Netherlands). Animals were socially housed in Plexiglas cages and had ad-libitum access to water, except during the experimental sessions. A 12-hr reversed light-dark cycle was maintained, with lights on at 20:00 p.m. Throughout the setshifting experiment, a 22-h food-restriction schedule was maintained, with $2 \mathrm{~h}$ of unlimited food access after each session. Experimental sessions were performed in four identical operant chambers (Med Associates) equipped with a red house-light, a food magazine for 45-mg food pellet delivery, and two retractable levers. Above each lever a green light emitting diode (LED) stimulus light was present, which was used as visual stimulus. Eight 5-HTT ${ }^{+/+}$and eight 5-HTT ${ }^{-/-}$rats underwent an adapted variant of the strategy set-shift paradigm described in full length by Floresco et al. (2008). In short, during the pretraining phase, rats were trained under a fixed-ratio 1 schedule for food reward in the form of sucrose pellets ( $45 \mathrm{mg}$, Bio Serv) to a criterion of 50 presses in $30 \mathrm{~min}$, first for one lever, then the other (counterbalanced left/right between rats). One $5-\mathrm{HTT}^{-/-}$rat failed to learn to press for food during this phase and was excluded from the experiment. Subsequently, during the successive "lever insert pretraining" phase, animals were acquainted with the random insertion of both levers into the experimental chambers. Insertion of either lever was associated with the illumination of both visual 
stimulus lights above the levers, which were extinguished after the rat responded on the inserted lever. Animals had to achieve a criterion of less than five omissions over a total of 90 trials and received at least five sessions of lever insertion training. When criterion was achieved, animals proceeded to the "side bias test" in which the potential side bias of animals was determined. During this test, trials were given in trial blocks (eight in total), in which rats had to press both levers in subsequent trials, after which a new trial block commenced. Thus, trials started with both levers inserted in the chamber and in the very first trial, lever pressing on either lever resulted in a sucrose pellet delivery. For reinforcer delivery in subsequent trials, rats had to press the lever opposite the one chosen at first. In case the same lever was pressed, no pellet reward was delivered and the house light was extinguished. This continued until the rat chose the lever opposite to the one chosen at first. The side bias was determined by considering the initial side which the rat pressed during the trial blocks and the total presses on one side during the whole session. If the total number of presses on either the left or right side was comparable to the number of presses on the other lever, the side that the rat initially pressed the most was its side bias. However, if the total number of presses on one side was disproportionate (i.e., $>2: 1$ ) to the number of presses on the other side, the side with the most presses was considered the rat's biased side. After side bias was determined, rats subsequently learned during the "strategy training" phase to use an egocentric strategy (e.g., always press the left lever, irrespective of the location of the illuminated stimulus light) for food reward. The lever opposite the rat's preferred lever (as determined during the side bias test) was reinforced during this training. Rats continued to receive trials until either (1) at least 30 trials were completed and the criterion of eight consecutive correct responses was achieved or (2) after 120 trials, whichever came first. Trials in which the animal did not respond (i.e., omission trials) were not included in the trials to criterion measure. If rats did not succeed to reach the criterion measure within one session, the animal would receive a subsequent session of response training on the following day. After reaching criterion, rats proceeded with the subsequent "strategy set-shift" phase. Here, animals were required to cease the use of the formerly learned egocentric strategy and to shift toward the use of a visual stimulus-based strategy (i.e., always press the lever with the stimulus light illuminated above it, irrespective of left or right position). Rats continued to receive trials until either (1) a criterion performance of eight consecutive correct responses was achieved or (2) after 120 trials were given. Again, if a rat did not achieve criterion during one session, the animal received a subsequent session on the following day. The data of the strategy set-shift phase was additionally analyzed per block of 16 trials for three types of errors: perseverative errors, regressive errors, and never reinforced errors. Perseverative errors were scored when a rat pressed the lever without an illuminated stimulus light above it on the side that was initially reinforced during training. With regard to regressive errors, if a rat pressed less than six perseverative errors in a block of 16 trials, the consecutive errors of this type were described as regressive errors. Finally, never-reinforced errors were scored when a rat pressed the incorrect lever on trials using a strategy that was never reinforced during training or shift. Regressive and never-reinforced errors were used as an index of the animals' ability to maintain and acquire a new strategy, respectively (Floresco et al. 2008).

With regard to the results of the initial strategy training phase, a one-way ANOVA was performed using the trial-to-criterion data as dependent variable, and genotype as factor. This analysis revealed that 5- $\mathrm{HTT}^{+/+}$rats were not different from $5-\mathrm{HTT}^{-/-}$ rats in the number of trials needed to reach the criterion of eight consecutive correct trials $\left(F_{(1,13)}=0.752\right.$, not significant $\left.[\mathrm{NS}]\right)$ on performance (see Fig. 1A, left). During the subsequent strategy set-
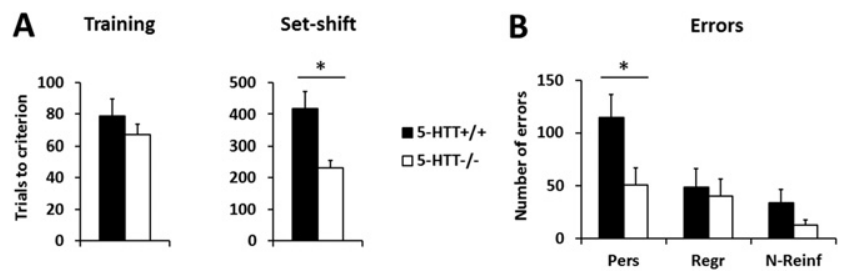

Figure 1. Performance of $5-\mathrm{HTT}^{+/+}$and $5-\mathrm{HTT}^{-/-}$rats during the training and strategy set-shifting phase. $(A)$ Mean $( \pm$ SEM) number of trials needed to reach the criterion of eight consecutive correct trials in the training (left) and set-shift (right) phases of the experiment. $(B)$ Types of errors made by $5-\mathrm{HTT}^{+/+}$and $5-\mathrm{HTT}^{-/-}$rats during the set-shift: Data represent mean $( \pm$ SEM) number of perseverative (Pers), regressive (Regr), and never-reinforced (N-Reinf) errors made before reaching criterion. (*) $P<0.05 .5-\mathrm{HTT}^{+/+}$vs. $5-\mathrm{HTT}^{-/-}$rats.

shifting phase, animals had to shift from the use of an egocentric strategy (as learned during the training phase) toward a strategy that depended on the use of visual stimuli in order to obtain food reward. A One-Way ANOVA indicated that $5-\mathrm{HTT}^{-/-}$rats needed considerably fewer trials to reach criterion than 5 -HTT ${ }^{+/+}$rats $\left(F_{(1,13)}=9.054, P<0.05\right)$ (see Fig. $1 \mathrm{~A}$, right). This was associated with a decreased amount of perseverative $\left(F_{(1,13)}=5.262, P<0.05\right)$, but not regressive $\left(F_{(1,13)}=0.108, \mathrm{NS}\right)$ or never-reinforced $\left(F_{(1,13)}=1.972, \mathrm{NS}\right)$ errors in 5 -HTT $^{-/-}$rats (see Fig. 1B). An additionally performed visual discrimination test indicated that the genotype differences in strategy set-shifting were not due to differences visual stimulus discrimination (see Supplemental Material).

The decrease in perseverative errors in $5-\mathrm{HTT}^{-/-}$rats relative to 5 -HTT ${ }^{+/+}$animals can be attributed to two different processes. It may be based on enhanced "unlearning" of the previous egocentric strategy, but can also reflect enhanced associative stimulus-reward learning. The former possibility is not very likely in view of the fact that the two genotypes did not differ in the number of never-reinforced errors, implicating that both groups were equally likely to try an entirely novel strategy. With respect to the latter possibility, during the initial training phase, the visual stimulus was irrelevant. In other words, this training can be conceptualized as "learned irrelevance" training, which the rats had to overcome after the shift. This exposure-induced learned irrelevance and associated decrement in learning a stimulus-reward association is similar to the phenomenon of latent inhibition (Lubow 1973). To further investigate the validity of a learned irrelevance account, an additional batch of animals was tested in a latent inhibition task, which used an auditory stimulus as conditioned stimulus (CS) and sucrose pellets as positive reinforcer. A total of four groups (pre $5-\mathrm{HTT}^{+/+}[n=8]$, no-pre 5 -HTT $\mathrm{HT}^{+/+}$ $[n=7]$, pre $5-\mathrm{HTT}^{-/-}[n=8]$, no-pre $\left.5-\mathrm{HTT}^{-/-}[n=8]\right)$ of rats were tested in a previously described setup (Nonkes et al. 2010). All animals were food deprived $2 \mathrm{~h}$ before experimental testing and received two sessions of magazine training to ensure frequent visits to the food magazine ( 15 pellet deliveries on a random interval schedule of $4 \mathrm{~min} \pm 25 \%$ ). Subsequently, pre 5 - $\mathrm{HTT}^{+/+}$and pre 5 -HTT ${ }^{-1-}$ rats received pre-exposure consisting of six sessions, during which rats were exposed 10 times to a $3-\mathrm{kHz}$ auditory CS $(76 \mathrm{~dB}, 30 \mathrm{sec})$ at a 4 -min intertrial interval $( \pm 25 \%)$. Rats of the no-pre $5-\mathrm{HTT}^{-/-}$and no-pre $5-\mathrm{HTT}^{+/+}$groups were placed in the Skinner boxes for an equal amount of time, but without the tone presentations. Successively, all animals received eight conditioning sessions, during which the CS was presented 10 times at a 4-min intertrial interval ( $\pm 25 \%)$. The end of each CS coincided with the delivery of a sucrose pellet to the food magazine. The number of visits to the food magazine was measured during 
each tone (A) and in the 30 sec preceding each tone (B). An elevation $(\mathrm{A} / \mathrm{A}+\mathrm{B})$ ratio score was used as a measure of conditioning.

A repeated measures ANOVA on the elevation ratio with treatment (pre-exposure vs. no-pre-exposure) and session as within-subjects factors, and genotype as between-subjects factor, revealed a main treatment effect $\left(F_{(1,27)}=22.391, P<0.0005\right)$, which is indicative of retarded conditioning in the pre-exposure groups. The significant treatment $\mathrm{x}$ session interaction $\left(F_{(7,189)}=\right.$ 4.201, $P<0.0005$ ) indicated that the effect of the exposure treatment was most prominent in the first half of the conditioning sessions. More importantly, there was also a significant genotype $\mathrm{x}$ treatment interaction effect $\left(F_{(1,27)}=4.721, P<\right.$ 0.05 ) (see Fig. 2). Further analysis of this interaction revealed that pre $5-\mathrm{HTT}^{+/+}\left(F_{(1,13)}=18.254, P=0.01\right)$, but not pre 5 -HTT ${ }^{-/-}\left(F_{(1,14)}=4.483, \mathrm{NS}\right)$, rats showed a significant reduction in conditioning compared with their no-pre-group counterparts.

In summary, we show here that $5-\mathrm{HTT}^{-/-}$rats outperformed $5-\mathrm{HTT}^{+/+}$rats in an EDSS procedure. This improvement in $5-\mathrm{HTT}^{-/-}$animals was accompanied by a reduced number of perseverative errors. In the additionally performed latent inhibition paradigm it was found that $5-\mathrm{HTT}^{+/+}$rats showed a clear latent inhibition effect after pre-exposure, whereas 5 -HTT ${ }^{-/-}$rats failed to do so. Therefore, it is conceivable that reduced latent inhibition/learned irrelevance effects contributed to the improved setshifting performance of $5-\mathrm{HTT}^{-/-}$rats. The observation that $5-\mathrm{HTT}^{-/-}$rats showed a reduced number of perseverative errors-which occur during the early phase of the shift, the period during which latent inhibition effects can be expected-but not regressive or never-reinforced errors supports this notion.

The prefrontal cortical areas are essential for behavioral flexibility. Specifically, the orbitofrontal cortex (OFC) is implicated in reversal learning (McAlonan and Brown 2003; Ghods-Sharifi et al. 2008), the medial prefrontal cortex (mPFC) in extradimensional (strategy) set-shifting (Ragozzino et al. 1999; Floresco et al. 2008), and latent inhibition paradigms (George et al. 2010). As anatomical and task-related functional changes in these regions have been reported in 5-HTT ${ }^{-/-}$rodents (Wellman et al. 2007; Nonkes et al. 2010; Pang et al. 2011), the observed genotype differences in reversal learning (Nonkes et al. 2011) and the EDSS and latent inhibition paradigms (present study) might relate to altered OFC and mPFC function. In line, we specifically observed a genotype effect on mPFC-dependent perseverative errors, but not regressive or never-reinforced errors, which are thought to be more striatum-dependent (Floresco et al. 2009).

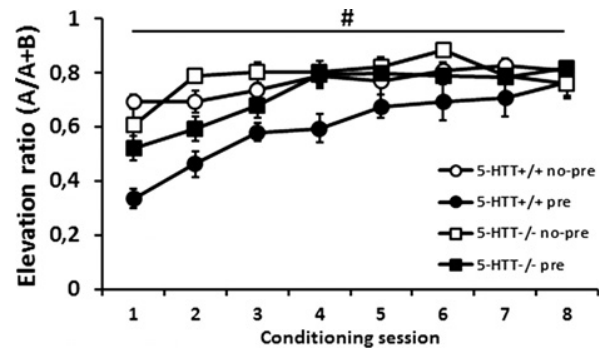

Figure 2. Latent inhibition in $5-\mathrm{HTT}^{+/+}$and $5-\mathrm{HTT}^{-/-}$rats. Data represent the increase in conditioned responding to the visual cue that was used as CS across conditioning sessions in the final phase of the latent inhibition experiment. Animals of each genotype had either received (pre) or not received (no-pre) nonreinforced pre-exposures to the CS. Conditioning was indexed as the mean ( \pm SEM) ratio based on the number of visits to the food magazine during the auditory cue $(A)$ and in the $30 \mathrm{sec}$ preceding each cue ( $B$; elevation ratio). (\#) $P<0.05$, genotype $\mathrm{x}$ treatment interaction.
One limitation of the present study is that we did not incorporate a retention test after the set-shift training phase to determine whether a consolidation and/or retention deficit may have contributed to the improved $5-\mathrm{HTT}^{-/-}$rats' set-shifting performance. However, previous experiments performed with 5 -HTT ${ }^{-/-}$rats did not provide any evidence for the notion that 5 -HTT ${ }^{-1-}$ rats exhibit a consolidation/retention deficit (e.g., Nonkes et al. 2010, 2011). Hence, it is unlikely that this contributed to the observed improved set-shift performance. Another limitation is that we tested the animals for strategy set-shifting in a noncounterbalanced design. Thus, rats were tested only in a one shift-direction (egocentric stimulus - $>$ visual stimulus). As such, it remains to be clarified whether true attentional set-shifting is affected by 5-HTT genotype or discrimination learning (Baxter and Gaffan 2007). Nevertheless, the results from the performed latent inhibition task suggest that alterations in 5-HTT levels do affect attentional processes.

Our study complements earlier ones, indicating that 5-HTT genetic variance affects, next to emotionality, aspects of cognitive functioning (Homberg and Lesch 2011). As such, 5-HTT genetic down-regulation may make an individual more vulnerable for developing anxiety- and depression-like symptoms (Caspi et al. 2010). However, the same genetically linked trait may contribute to behavioral flexibility, potentially through a hyper-reactive mPFC (Heinz et al. 2005) and OFC (Kalin et al. 2008). 5-HTT genetic variance may therefore be an important mediator for how an individual interacts with its environment, for better and for worse.

\section{Acknowledgments}

We thank A. Afrasiab-Middelman, H. Krijnen, and S. Hermeling for their help with the animal care. This work was funded by The Netherlands Organization for Scientific Research (NWO), grant \#86410003, awarded to J.H.R.M. NWO had no further role in the design of the study; in the collection, analysis, and interpretation of data; in the writing of the report; or in the decision to submit the paper for publication.

\section{References}

Baxter MG, Gaffan D. 2007. Asymmetry of attentional set in rhesus monkeys learning colour and shape discriminations. QJ Exp Psychol (Hove) 60: 1-8.

Borg J, Henningsson S, Saijo T, Inoue M, Bah J, Westberg L, Lundberg J, Jovanovic H, Andree B, Nordstrom AL, et al. 2009. Serotonin transporter genotype is associated with cognitive performance but not regional 5-HT1A receptor binding in humans. Int $J$ Neuropsychopharmacol 12: 783-792.

Brigman JL, Mathur P, Harvey-White J, Izquierdo A, Saksida LM, Bussey TJ, Fox S, Deneris E, Murphy DL, Holmes A. 2010. Pharmacological or genetic inactivation of the serotonin transporter improves reversal learning in mice. Cereb Cortex 20: 1955-1963.

Caspi A, Sugden K, Moffitt TE, Taylor A, Craig IW, Harrington H, McClay J, Mill J, Martin J, Braithwaite A, et al. 2003. Influence of life stress on depression: Moderation by a polymorphism in the 5-HTT gene. Science 301: 386-389.

Caspi A, Hariri AR, Holmes A, Uher R, Moffitt TE. 2010. Genetic sensitivity to the environment: The Case of the serotonin transporter gene and its implications for studying complex diseases and traits. Am J Psychiatry 167: 509-527.

Cools R, Roberts AC, Robbins TW. 2008. Serotoninergic regulation of emotional and behavioural control processes. Trends Cogn Sci 12: 31-40.

Dolan RJ. 2007. The human amygdala and orbital prefrontal cortex in behavioural regulation. Philos Trans R Soc Lond B Biol Sci 362: 787-799.

Floresco SB, Block AE, Tse MT. 2008. Inactivation of the medial prefrontal cortex of the rat impairs strategy set-shifting, but not reversal learning, using a novel, automated procedure. Behav Brain Res 190: 85-96.

Floresco SB, Zhang Y, Enomoto T. 2009. Neural circuits subserving behavioral flexibility and their relevance to schizophrenia. Behav Brain Res 204: 396-409. 
George DN, Duffaud AM, Pothuizen HH, Haddon JE, Killcross S. 2010. Lesions to the ventral, but not the dorsal, medial prefrontal cortex enhance latent inhibition. Eur J Neurosci 31: 1474-1482.

Ghods-Sharifi S, Haluk DM, Floresco SB. 2008. Differential effects of inactivation of the orbitofrontal cortex on strategy set-shifting and reversal learning. Neurobiol Learn Mem 89: 567-573.

Hariri AR, Holmes A. 2006. Genetics of emotional regulation: The role of the serotonin transporter in neural function. Trends Cogn Sci 10: $182-191$.

Hariri AR, Mattay VS, Tessitore A, Kolachana B, Fera F, Goldman D, Egan MF, Weinberger DR. 2002. Serotonin transporter genetic variation and the response of the human amygdala. Science 297: 400-403.

Heinz A, Braus DF, Smolka MN, Wrase J, Puls I, Hermann D, Klein S, Grusser SM, Flor H, Schumann G, et al. 2005. Amygdala-prefrontal coupling depends on a genetic variation of the serotonin transporter. Nat Neurosci 8: 20-21.

Homberg JR, Lesch KP. 2011. Looking on the bright side of serotonin transporter gene variation. Biol Psychiatry 69: 513-519.

Homberg JR, Olivier JD, Smits BM, Mul JD, Mudde J, Verheul M, Nieuwenhuizen OF, Cools AR, Ronken E, Cremers T, et al. 2007. Characterization of the serotonin transporter knockout rat: A selective change in the functioning of the serotonergic system. Neuroscience 146: $1662-1676$.

Jedema HP, Gianaros PJ, Greer PJ, Kerr DD, Liu S, Higley JD, Suomi SJ, Olsen AS, Porter JN, Lopresti BJ, et al. 2010. Cognitive impact of genetic variation of the serotonin transporter in primates is associated with differences in brain morphology rather than serotonin neurotransmission. Mol Psychiatry 15: 512-522.

Kalin NH, Shelton SE, Fox AS, Rogers J, Oakes TR, Davidson RJ. 2008. The serotonin transporter genotype is associated with intermediate brain phenotypes that depend on the context of eliciting stressor. $\mathrm{Mol}$ Psychiatry 13: 1021-1027.

Kalueff AV, Olivier JD, Nonkes LJ, Homberg JR. 2010. Conserved role for the serotonin transporter gene in rat and mouse neurobehavioral endophenotypes. Neurosci Biobehav Rev 34: 373-386.

Keeler JF, Robbins TW. 2011. Translating cognition from animals to humans. Biochem Pharmacol 81: 1356-1366.

Lesch KP, Bengel D, Heils A, Sabol SZ, Greenberg BD, Petri S, Benjamin J, Muller CR, Hamer DH, Murphy DL. 1996. Association of anxiety-related traits with a polymorphism in the serotonin transporter gene regulatory region. Science 274: $1527-1531$.

Lowry CA, Hale MW, Evans AK, Heerkens J, Staub DR, Gasser PJ, Shekhar A. 2008. Serotonergic systems, anxiety, and affective disorder: Focus on the dorsomedial part of the dorsal raphe nucleus. Ann N Y Acad Sci 1148: 86-94.

Lubow RE. 1973. Latent inhibition. Psychol Bull 79: 398-407.

McAlonan K, Brown VJ. 2003. Orbital prefrontal cortex mediates reversal learning and not attentional set shifting in the rat. Behav Brain Res 146: 97-103.

Merens W, Willem Van der Does AJ, Spinhoven P. 2007. The effects of serotonin manipulations on emotional information processing and mood. J Affect Disord 103: 43-62.

Nonkes LJ, Tomson K, Maertin A, Dederen J, Maes JH, Homberg J. 2010. Orbitofrontal cortex and amygdalar over-activity is associated with an inability to use the value of expected outcomes to guide behaviour in serotonin transporter knockout rats. Neurobiol Learn Mem 94: 65-72.

Nonkes LJ, Maes JH, Homberg JR. 2011. Improved cognitive flexibility in serotonin transporter knockout rats is unchanged following chronic cocaine self-administration. Addict Biol doi: 10.1111/ j.1369-1600.2011.00351.x.

Pacheco J, Beevers CG, Benavides C, McGeary J, Stice E, Schnyer DM. 2009. Frontal-limbic white matter pathway associations with the serotonin transporter gene promoter region (5-HTTLPR) polymorphism. $J$ Neurosci 29: 6229-6233.

Pang RD, Wang Z, Klosinski LP, Guo Y, Herman DH, Celikel T, Dong HW, Holschneider DP. 2011. Mapping functional brain activation using [C]-iodoantipyrine in male serotonin transporter knockout mice. PLoS One 6: e23869. doi: 10.1371/journal.pone.0023869.

Pezawas L, Meyer-Lindenberg A, Drabant EM, Verchinski BA, Munoz KE, Kolachana BS, Egan MF, Mattay VS, Hariri AR, Weinberger DR. 2005. 5-HTTLPR polymorphism impacts human cingulate-amygdala interactions: A genetic susceptibility mechanism for depression. Nat Neurosci 8: 828-834.

Ragozzino ME. 2007. The contribution of the medial prefrontal cortex, orbitofrontal cortex, and dorsomedial striatum to behavioral flexibility. Ann N Y Acad Sci 1121: 355-375.

Ragozzino ME, Detrick S, Kesner RP. 1999. Involvement of the prelimbicinfralimbic areas of the rodent prefrontal cortex in behavioral flexibility for place and response learning. J Neurosci 19: 4585-4594.

Wellman CL, Izquierdo A, Garrett JE, Martin KP, Carroll J, Millstein R, Lesch KP, Murphy DL, Holmes A. 2007. Impaired stress-coping and fear extinction and abnormal corticolimbic morphology in serotonin transporter knock-out mice. J Neurosci 27: 684-691.

Received February 8, 2012; accepted in revised form March 1, 2012. 


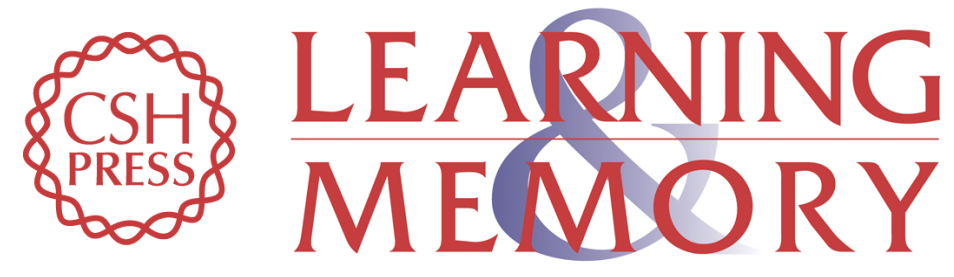

\section{Serotonin transporter knockout rats show improved strategy set-shifting and reduced latent inhibition}

Lourens J.P. Nonkes, Ilse I.G.M. van de Vondervoort, Mark J.C. de Leeuw, et al.

Learn. Mem. 2012, 19:

Access the most recent version at doi:10.1101/Im.025908.112

Supplemental
Material http://learnmem.cshlp.org/content/suppl/2012/04/13/19.5.190.DC1

References This article cites 33 articles, 6 of which can be accessed free at: http://learnmem.cshlp.org/content/19/5/190.full.html\#ref-list-1

License

Email Alerting Receive free email alerts when new articles cite this article - sign up in the box at the Service top right corner of the article or click here. 